\title{
ANALISIS KESANTUNAN BERBAHASA DALAM NOVEL "PULANG" KARYA TERE LIYE
}

\author{
Hikmah Amelia ${ }^{1}$, Usman M. ${ }^{2}$ dan Yusmah ${ }^{3}$ \\ 1, 2,3 Universitas Muhammadiyah Sidenreng Rappang \\ Jl. Angkatan 45 No 1A Lautang Salo Rappang, Pancarijang, Sidenreng Rappang \\ hikmahameliasusa@gmail.com
}

\begin{abstract}
Abstrak: Analisis Kesantunan Berbahasa dalam Novel 'Pulang' Karya Tere Liye. Penelitian ini bertujuan untuk mengetahui kesantunan berbahasa yang terdapat dalam novel pulang karya Tere Liye. Penelitian ini berdasar pada prinsip kesantunan Leech yang terdiri atas maksim kebijaksanaan, maksim kedermawanan, maksim penghargaan, maksim kesederhanaan, maksim permufakatan, dan maksim kesimpatian. Metode yang digunakan dalam penelitian ini adalah metode deskriptif kualitatif. Data dalam penelitian ini berupa tuturan tokoh dalam novel Pulang karya Tere Liye. Sumber data penelitian ini ialah novel "Pulang karya Tere Liye, yang terdiri atas 400 halaman yang diterbitkan oleh Republika penerbit. Teknik pengumpulan data yang digunakan ialah reduksi data. Hasil penelitian menunjukkan bahwa terdapat 40 tuturan yang mematuhi maksim kebijaksanaan, terdapat 17 tuturan yang mematuhi maksim kedermawanan, terdapat 90 tuturan yang mematuhi maksim penghargaan, terdapat 41 tuturan yang mematuhi maksim kesederhanaan, terdapat 54 tuturan yang mematuhi maksim permufakatan, dan terdapat 155 tuturan yang mematuhi maksim kesimpatian.
\end{abstract}

Kata kunci : kesantunan berbahasa, maksim kesantunan, Tere Liye

Abstract: Analysis of Language Impressions in Tere Liye's Novel 'Pulang'. This research aims to find out the language impressions contained in tere liye's return novel. This research is based on the principle of Leech impression consisting of maksim wisdom, maksim generosity, maksim appreciation, maksim simplicity, maksim permufakatan, and maksim sympathy. The method used in this study is a qualitative descriptive method. The data in this study is in the form of the speech of a character in the novel Pulang by Tere Liye. The source of this research data is the novel "Pulang by Tere Liye, which consists of 400 pages published by Republika publishers. The data collection technique used is data reduction. The results showed that there were 40 speeches that complied with maksim wisdom, there were 17 speeches that adhered to the maksim of generosity, there were 90 speeches that complied with maksim awards, there were 41 speeches that adhered to the maksim of sympathy, and there were 155 speeches that adhered to the maksim of sympathy.

Keywords : language impression, maksim kesantunan, Tere Liye. 
Pragmatik merupakan salah satu cabang ilmu tata bahasa yang berkaitan erat dengan tindak ujar. Pragmatik mempelajari apa saja yang termasuk struktur bahasa sebagai alat komunikasi antara penutur dan mitra tutur serta sebagai pengacauan tandatanda bahasa yang sifatnya ekstralinguistik. Di dalam ilmu pragmatik, bahasa diteliti tidak lepas dan harus sesuai dengan konteks bahasa yang dimaksud.

Konteks penggunaan sebuah ujaran dapat memengaruhi maksud dan tujuan dari tindak ujar yang disampaikan oleh pelaku tindak ujar. Selain itu, agar tujuan penutur tercapai maka dalam bertutur diperlukan sikap santun, yakni kesantunan dalam berbahasa. Memahami makna tuturan dilakukan dengan menganalisis wujud, fungsi, dan strategi kesantunan berbahasa (Sadapotto, 2016: 548-549).

Kesantunan berbahasa tidak hanya diterapkan melalui interaksi sehari-hari atau komunikasi dikehidupan sehari-hari. Namun, kesantunan berbahasa juga diterapkan dalam penulisan karya sastra, misalnya novel.

Karya sastra novel dalam penyajiannya lebih dominan bersifat narasi dan deskripsi. Pendeskripsian dalam novel bersifat lebih mendetail atau terperinci. Selain itu dalam sebuah novel, cerita menjadi lebih hidup karena disisipi interaksi antara tokoh dalam suatu konteks atau situasi tertentu. Oleh karena itu, pragmatik dapat mengkaji kesantunan berbahasa yang terdapat dalam sebuah novel karena adanya interaksi tokoh berdasarkan konteks atau situasi tertentu.

Novel yang dianalisis dalam penelitian ini ialah Pulang karya Tere Liye. Novel ini bertema seorang anak laki-laki yang dibesarkan oleh keluarganya yang terusir dari kampung halaman, mencoba mencari jati diri dan hakikat kehidupannya. Novel ini merupakan novel yang pertama kali dicetakan pada tahun 2015. Alur cerita yang disajikan dalam novel ini bersifat maju mundur. Serta ceritanya yang berbeda dari novel-novel roman yang muncul pada masa sekarang.
Novel ini telah menarik perhatian penulis untuk menjadikan novel ini sebagai sumber dalam penelitian ini, yang berkaitan dengan ilmu pragmatik mengenai kesantunan berbahasa.

\section{METODE}

Penelitian ini merupakan penelitian kulalitatif yang menghasilkan data deskriptif berupa kata-kata tertulis dari data yang diteliti. Desain penelitian ini dianggap sesuai untuk menganalisis kesantunan berbahasa dalam novel Pulang karya Tere Liye.

Data dalam penelitian ini berupa tuturan tokoh dalam novel Pulang karya Tere Liye. Sumber data penelitian ini ialah novel "Pulang karya Tere Liye, yang terdiri atas 400 halaman yang diterbitkan oleh Republika penerbit.

Teknik pengumpulan data yang digunakan ialah membaca dan mencatat data. Teknik membaca yaitu peneliti membaca secara menyeluruh novel yang akan diteliti dalam hal ini novel Pulang karya Tere Liye. Selanjutnya, teknik mencatat data yaitu peneliti akan mencatat data yang mengandung maksim prinsip kesantunan berbahasa menurut Leech.

Teknik analisis data yang dilakukan ialah peneliti melakukakan reduksi data, penyajian data dan penarikan kesimpulan. Reduksi data yaitu proses penyeleksian, pemfokusan, penyederhanaan dan pengelompokan data yang telah diperoleh dalam pengumpulan data. Kemudian penyajian data yaitu menyajikan data secara sistematis agar mudah dibaca dan dipahami. Lalu penarikan kesimpulan yaitu paparan atau penjelasan yang dilakukan dengan melihat kembali pada data reduksi maupun penyajian data, sehingga kesimpulan yang diambil tidak menyimpang dari data yang dianalisis.

Agar pembaca lebih mudah memahami analisis, maka penulis memberi kode penamaan tuturan untuk setiap bagian dari novel, beserta halamannya. Terdapat 25 bagian dalam novel, yaitu dengan judul $\mathrm{Si}$ Babi Hutan, janji Kepada Mamak, Shadow Economy, Penunggang Kuda Suku Bedouin, 
Amok, Patung Naga Emas, Pencuri yang Pengecut, Tim Terbaik, Penyerbuan Kasino, Pindah ke Ibu Kota, Latihan Menembak, Mamak Pergi, Salonga dari Tondo, Belajar Hingga Negeri Seberang, Surat dari Bapak, Pengkhianatan (Bag. Satu), Utang 40 Juta Dolar, Pengkhianatan (Bag. Dua), Tuanku Imam, Suara Adzan, Memeluk Erat, Kesetiaan yang Memanggil, Lantai Dua Puluh Lima, Samurai Sejati, dan Epilog:
Pulang. Maka, penulis memberi kode berupa angka 1-25 sesuai urutan bagian dalam novel.

\section{HASIL DAN PEMBAHASAN}

\section{Hasil Penelitian}

Hasil penelitian ini berupa tuturan yang mematuhi maksim kesantunan berdasarkan prinsip kesantunan Leech.

a. Maksim Kebijaksanaan

Adapun temuan tuturan yang mematuhi maksim kebijaksanaan dalam novel pulang karya Tere Liye yaitu terdapat 40 tuturan. Dapat dilihat pada tabel 1

Tabel 1 Maksim Kebijaksanaan

\begin{tabular}{|c|c|c|c|}
\hline No. & $\mathrm{Bab} ; \mathrm{Hal}$ & Tuturan & Analisis \\
\hline 1 & $1 ; 3$ & $\begin{array}{l}\text { "Kalian naiklah ke atas, istriku sudah } \\
\text { menyediakan kopi dan juadah. Kita } \\
\text { bisa bicara sambil sarapan..." }\end{array}$ & $\begin{array}{lcr}\text { Samad } & \text { memaksimalkan } & \text { keuntungan } \\
\text { mitra } & \text { tuturnya } & \text { dengan } \\
\text { mempersilahkannya makan. } & \end{array}$ \\
\hline 2 & $1 ; 10$ & $\begin{array}{l}\text { "Kau kenakan jaket hujan ini, } \\
\text { Bujang." Tauke Muda melemparkan } \\
\text { jaket gelap. }\end{array}$ & $\begin{array}{l}\text { Tauke memaksimalkan keuntungan } \\
\text { Bujang dengan memberikan jaket } \\
\text { kepadanya. }\end{array}$ \\
\hline 3 & $3 ; 27$ & $\begin{array}{l}\text { "Silahkan duduk. Ayo, jangan } \\
\text { sungkan-sungkan." }\end{array}$ & $\begin{array}{lrr}\text { Calon Presiden memaksimalkan } \\
\text { keuntungan Bujang dengan } \\
\text { mempersilahkannya duduk } \\
\text { menawarkan minuman. }\end{array}$ \\
\hline 4 & $3 ; 29-30$ & $\begin{array}{l}\text { "Jika Anda tidak tahu, maka } \\
\text { penasihat ekonomi yang duduk di } \\
\text { sebelah Anda bisa menjelaskan lebih } \\
\text { baik. Dia menyelesaikan kuliah } \\
\text { ekonomi di Amerika dengan nilai } \\
\text { baik. Tapi akan aku jeaskan secara } \\
\text { singkat pokok besarnya." }\end{array}$ & $\begin{array}{l}\text { Bujang berusaha } \\
\text { memaksimalkan } \\
\text { keuntungan Calon Presiden dengan } \\
\text { menjelaskan secara singkat pokok } \\
\text { besar tentang shadoweconomy. }\end{array}$ \\
\hline 5 & $4 ; 37$ & $\begin{array}{l}\text { "Ada masalah? Apakah kau butuh } \\
\text { bantuanku?" }\end{array}$ & $\begin{array}{l}\text { Basyir berusaha memaksimalkan } \\
\text { keuntungan Bujang, dengan } \\
\text { menawarkan bantuan. }\end{array}$ \\
\hline 6 & $4 ; 46$ & $\begin{array}{l}\text { "Duduklah. Aku masih ada beberapa } \\
\text { pekerjaan kau tunggu sebentar." }\end{array}$ & $\begin{array}{l}\text { Tauke memaksimalkan keuntungan } \\
\text { Bujang, menyuruhnya duduk sambil } \\
\text { menunggu Tauke menyelesaikan } \\
\text { pekerjaannya. }\end{array}$ \\
\hline 7 & $5 ; 59$ & $\begin{array}{l}\text { "Biar aku yang memasangnya. Halo, } \\
\text { Dok. Apakah ini pemeriksaan rutin?" }\end{array}$ & $\begin{array}{l}\text { Bujang memaksimalkan keuntungan } \\
\text { perawatan yang masih takut kepada } \\
\text { Tauke dengan menawarkan diri } \\
\text { memasangkan peralatan kepada Tauke. }\end{array}$ \\
\hline 8 & $5 ; 63$ & $\begin{array}{l}\text { "Kau selalu saja menghindar } \\
\text { membicarakan ini. Untuk seseorang } \\
\text { yang telah membunuh banyak orang, } \\
\text { menghabisi dengan mudah lawan- } \\
\text { lawannya, kau seharusnya santai saja } \\
\text { membicarakan kematianku. Aku akan } \\
\text { mati. Sama seperti Samad dan } \\
\text { mamak kau di lereng hutan sana. } \\
\text { Dikubur dalam tanah, dimakan }\end{array}$ & $\begin{array}{l}\text { Tauke memaksimalkan keuntungan } \\
\text { Bujang dengan memaksanya berbicara } \\
\text { sore ini agar tidak mencemaskan } \\
\text { kematian Tauke. }\end{array}$ \\
\hline
\end{tabular}




\begin{tabular}{|c|c|c|c|}
\hline & & $\begin{array}{l}\text { cacing. Kuburkan aku segera tanpa } \\
\text { harus menungg siapa pun agar semua } \\
\text { bisa dilupakan dnegan cepat. Dan } \\
\text { kenapa aku memaksamu bicara sore } \\
\text { ini, agar kau berhenti mencemaskan } \\
\text { kematianku. Ada yang lebih serius } \\
\text { yang harus kau cemaskan. } \\
\text { Pertempuran besar." }\end{array}$ & \\
\hline 9 & $5 ; 65$ & $\begin{array}{l}\text { "...Aku akan segera mengumumkan } \\
\text { kau adalah calon kepala keluarga } \\
\text { baru, setelah kau kembali dari Hong } \\
\text { Kong. Itu akan membuat posisi kita } \\
\text { kuat..." }\end{array}$ & $\begin{array}{l}\text { Tauke memaksimalkan keuntungan } \\
\text { Bujang beserta Keluarga Tong dengan } \\
\text { menjadikan Bujang sebagai Tauke } \\
\text { Muda. }\end{array}$ \\
\hline 10 & $6 ; 76$ & $\begin{array}{l}\text { "Kau datang terlambat, tapi makanan } \\
\text { lezat masih terhidang. Cepat, } \\
\text { hidangkan makanan untuknya." }\end{array}$ & 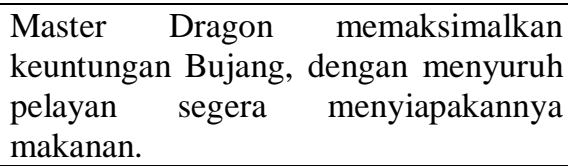 \\
\hline
\end{tabular}

dst...

b. Maksim Kedermawanan

Adapun temuan tuturan yang mematuhi maksim kedermawanan dalam novel Pulang karya Tere Liye yaitu sebanyak 17 tuturan. Dapat dilihat dalam tabel 2.

Tabel 2 Maksim Kedermawanan

\begin{tabular}{|c|c|c|c|}
\hline No. & Bab;Hal & Tuturan & Analisis \\
\hline 1 & $2 ; 23$ & $\begin{array}{l}\text { "Mamak akan mengizinkan kau } \\
\text { pergi, Bujang. Meski itu sama saja } \\
\text { dengan merobek separuh hati } \\
\text { Mamak. Pergilah, anakku, temukan } \\
\text { masa depanmu. Sungguh, besok lusa } \\
\text { kau akan pulang. Jika tidak ke } \\
\text { pangkuan Mamak, kau akan pulang } \\
\text { pada hakikat sejati yang ada di dalam } \\
\text { dirimu. Pulang..." }\end{array}$ & $\begin{array}{l}\text { Midah, Mamak Bujang menambah } \\
\text { keuntungan Bujang dengan } \\
\text { mengizinkannya ke Kota untuk } \\
\text { menemukan masa depannya meski ia } \\
\text { merasa seperti merobek separuh } \\
\text { hatinya atas kepergian Bujang. }\end{array}$ \\
\hline 2 & $3 ; 28$ & $\begin{array}{l}\text { "Baiklah kalau begitu. Apa yang bisa } \\
\text { kubantu? Aku baru saja menerima } \\
\text { agenda ini. Sangat mendadak, terus } \\
\text { terang. Aku seharusnya berkampanye } \\
\text { di kota penting siang ini. Tapi } \\
\text { penasihat ekonomiku mendesak, } \\
\text { bilang pertemuan ini serius. Apakah } \\
\text { ini soal dana kampanye ? Dukungan } \\
\text { dari para pengusaha?" }\end{array}$ & $\begin{array}{l}\text { Calon Presiden bertemu dengan } \\
\text { Bujang padahal ia juga memiliki } \\
\text { agenda lain yang bersamaan dengan } \\
\text { pertemuan Bujang yang tiba-tiba. }\end{array}$ \\
\hline 3 & $4 ; 39$ & "Kau periksa dia lebih dulu." & $\begin{array}{l}\text { Tauke menyuruh dokter memeriksa } \\
\text { Bujang terlebih dahulu padahal ia } \\
\text { juga memiliki luka. }\end{array}$ \\
\hline 4 & $4 ; 40$ & $\begin{array}{l}\text { "Nanti, setelah aku mengantarnya ke } \\
\text { mess sayap kanan. Kau obati yang } \\
\text { lain dulu." }\end{array}$ & $\begin{array}{l}\text { Tauke menambah keuntungan kepada } \\
\text { Bujang dengan mengantarnya ke } \\
\text { mess, menyuruh dokter mengobati } \\
\text { yang lain dulu padahal ia juga } \\
\text { memiliki luka yang harus diobati. }\end{array}$ \\
\hline 5 & $6 ; 68$ & 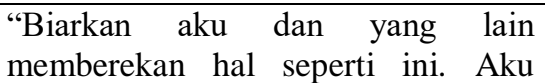 & $\begin{array}{l}\text { Basyir memaksimalkan keuntungan } \\
\text { Bujang, dengan cara ia dan tukang }\end{array}$ \\
\hline
\end{tabular}




\begin{tabular}{|c|c|c|c|}
\hline & & $\begin{array}{l}\text { pastikan, sekembalinya kau dari } \\
\text { Hong Kong, situasi kembali normal. } \\
\text { Dan keluarga kita bisa bersiap } \\
\text { menyambut calon kepala keluarga } \\
\text { baru. Aku mungkin tidak memanggil } \\
\text { namamu langsung, aku harus mulai } \\
\text { berlatih memanggilmu, Tauke } \\
\text { Muda." }\end{array}$ & $\begin{array}{l}\text { pukul lain yang akan membereskan } \\
\text { keluarga tersebut. Sehingga saat } \\
\text { Bujang kembali semuanya kembali } \\
\text { normal. }\end{array}$ \\
\hline 6 & $6 ; 70$ & "Tidak masalah, Capt." & $\begin{array}{l}\text { Edwin memaksimalkan keuntungan } \\
\text { Bujang dengan menerbangkan } \\
\text { pesawat sendiri, membiarkan Bujang } \\
\text { menyelesaikan pekerjaan lain di } \\
\text { kabin. }\end{array}$ \\
\hline 7 & $9 ; 132$ & "Kau duluan, Bujang." & $\begin{array}{l}\text { White memaksimalkan keuntungan } \\
\text { Bujang dengan menyuruhnya duluan, } \\
\text { membiarkan dirinya menahan tukang } \\
\text { pukul lain lalu, meluncur terakhir. }\end{array}$ \\
\hline 8 & $12 ; 186$ & $\begin{array}{l}\text { "Tidak. Aku tidak akan } \\
\text { melakukannya." }\end{array}$ & $\begin{array}{l}\text { Bujang tidak mau menembakkan } \\
\text { pistol itu kepada Salonga walau ia } \\
\text { akan mendapat hukuman dari Tauke. }\end{array}$ \\
\hline 9 & $13 ; 207$ & $\begin{array}{l}\text { "Jika kau butuh bantuan, segera } \\
\text { hubungi aku, Bujang. Tondo punya } \\
\text { pasukan besar." }\end{array}$ & $\begin{array}{l}\text { Salonga menawarkan bantuan kepada } \\
\text { Bujang. }\end{array}$ \\
\hline 10 & $16 ; 248$ & $\begin{array}{l}\text { "Tunggu di sini. Biar aku yang } \\
\text { menyalakan dan membawa mobilnya, } \\
\text { Bujang." }\end{array}$ & $\begin{array}{l}\text { Joni memaksimalkan keuntungan } \\
\text { Parwez dan Bujang dengan } \\
\text { menyuruhnya menunggu dan biarkan } \\
\text { dia yang mengambil mobil. }\end{array}$ \\
\hline
\end{tabular}

dst...

c. Maksim Penghargaan

Adapun temuan tuturan yang mematuhi maksim penghargaan dalam novel pulang karya Tere Liye yaitu sebanyak 90 tuturan. Dapat dilihat pada tabel 3.

Tabel 3 Maksim Penghargaan

\begin{tabular}{|c|c|c|c|}
\hline No. & Bab; Hal & Tuturan & Analisis \\
\hline 1 & $1 ; 5$ & $\begin{array}{l}\text { Tubuhnya gagah besar } \text { seperti } \\
\text { bapaknya. Sudah seperti pemuda } \\
\text { dewasa. Matanya hitam tajam. Aku } \\
\text { suka dia. Kelas berapa kau } \\
\text { sekarang?" }\end{array}$ & $\begin{array}{l}\text { Tauke memberikan penghargaan } \\
\text { kepada Bujang, berkata bahwa } \\
\text { Bujang memiliki tubuh gagah basar } \\
\text { seperti Samad serta memiliki mata } \\
\text { hitam tajam dan diakhiri dengan } \\
\text { berkata bahwa Tauke menyukai } \\
\text { Bujang. }\end{array}$ \\
\hline 2 & $1 ; 5$ & $\begin{array}{l}\text { "Apakah kau pandai berburu babi } \\
\text { hutan seperti bapakmu?" }\end{array}$ & $\begin{array}{l}\text { Tokoh Tauke } \text { memberikan } \\
\text { penghargaan secara tidak langsung } \\
\text { berkata bahwa Samad pandai } \\
\text { berburu. }\end{array}$ \\
\hline 3 & $1 ; 6$ & $\begin{array}{l}\text { "Bagus sekali! Mari kita lihat } \\
\text { seberapa hebat kau di dalam sana. } \\
\text { Bapak kau ini dulu, adalah pemburu } \\
\text { yang hebat. Berikan senapan } \\
\text { padanya, dia akan menjatuhkan satu } \\
\text { persatu babi." }\end{array}$ & $\begin{array}{l}\text { Tauke memberikan penghargaan atas } \\
\text { jawaban Bujang yang setuju ikut } \\
\text { dengannya berburu. Selain itu, Tauke } \\
\text { juga memberi penghargaan terhadap } \\
\text { Bapak Bujang yang merupakan } \\
\text { pemburu hebat. }\end{array}$ \\
\hline 4 & $1 ; 8$ & $\begin{array}{l}\text { "...Seperti yang pernah kau lakukan } \\
\text { untuk ayahku dulu." }\end{array}$ & $\begin{array}{ll}\text { Tauke } & \text { memberikan penghargaan } \\
\text { bahwa } & \text { Samad pernah menjaga }\end{array}$ \\
\hline
\end{tabular}




\begin{tabular}{|c|c|c|c|}
\hline & & & ayahnya. \\
\hline 5 & $1 ; 9$ & $\begin{array}{l}\text { "Selamat, Bujang. Ini babi buruan } \\
\text { pertama kita." }\end{array}$ & $\begin{array}{l}\text { Tauke mengucapkan selamat kepada } \\
\text { Bujang, setelah } \\
\text { melumpuhkan babi. }\end{array}$ \\
\hline 6 & $2 ; 25$ & $\begin{array}{l}\text { "Sama seperti yang kau lakukan saat } \\
\text { menjaga Tauke Besar dulu. Dan dia } \\
\text { telah memulainya tadi malam, saat } \\
\text { seorang diri menaklukkan babi } \\
\text { raksasa. Dia akan tumbuh dengan } \\
\text { reputasi hebat. Semua orang akan } \\
\text { gemetar mendengar namanya disebut. } \\
\text { Aku bersumpah akan mengurus anak } \\
\text { kau, samad. Anak dari saudara } \\
\text { angkatku." }\end{array}$ & $\begin{array}{l}\text { Tauke memberikan penghargaan } \\
\text { kepada Samad dengan berkata "Sama } \\
\text { seperti yang kau lakukan saat } \\
\text { menjaga Tauke Besar dulu...". Selain } \\
\text { itu, juga memberikan penghargaan } \\
\text { karena Bujang seorang diri } \\
\text { menaklukkan babi raksasa ketika } \\
\text { berburu. }\end{array}$ \\
\hline 7 & $3 ; 29$ & $\begin{array}{l}\text { "Jika Anda tidak tahu, maka } \\
\text { penasihat ekonomi yang duduk di } \\
\text { sebelah Anda bisa menjelaskan lebih } \\
\text { baik. Dia menyelesaikan kuliah } \\
\text { ekonomi di Amerika dengan nilai } \\
\text { baik..." }\end{array}$ & $\begin{array}{l}\text { Bujang memberikan penghargaan } \\
\text { kepada penasehat ekonomi Calon } \\
\text { Presiden tersebut dengan berkata } \\
\text { bahwa penasehat tersebut bisa } \\
\text { menjelaskan tentang shadow } \\
\text { economy dengan lebih baik. Serta ia } \\
\text { menambahkan penghargaannya } \\
\text { dengan "...Dia } \\
\text { menyelesaikan kuliah ekonomi di } \\
\text { Amerika dengan nilai baik..." }\end{array}$ \\
\hline 8 & $3 ; 35$ & $\begin{array}{l}\text { "Baik. Tiga puluh menit telah habis. } \\
\text { Terima kasih atas waktunya." }\end{array}$ & $\begin{array}{l}\text { Bujang mengucapkan terima kasih } \\
\text { kepada Calon Presiden yang telah } \\
\text { meluangkan waktu untuknya. }\end{array}$ \\
\hline 9 & $4 ; 39$ & $\begin{array}{l}\text { "Dia baik-baik saja. Lukanya akan } \\
\text { sembuh dalam hitungan minggu } \\
\text { tanpa perlu dijahit. Anak ini punya } \\
\text { daya tahan fisik luar biasa. Dia bisa } \\
\text { istirahat sekarang, setelah } \\
\text { menghabiskan semangkuk sup } \\
\text { hangat." }\end{array}$ & $\begin{array}{l}\text { Ketika dokter memberi pujian bahwa } \\
\text { Bujang memiliki daya tahan fisik } \\
\text { yang luar biasa. }\end{array}$ \\
\hline 10 & $4 ; 40$ & "Bagus." & $\begin{array}{l}\text { Tauke mematuhi } \\
\text { penghargaan ketika ia berkata } \\
\text { "Bagus." Memberikan penghargaan } \\
\text { atas penjelasan dokter. }\end{array}$ \\
\hline
\end{tabular}

dst...

d. Maksim Kesederhanaan

Adapun temuan tuturan yang mematuhi maksim kesederhanaan dalam novel pulang karya Tere Liye yaitu sebanyak 41 tuturan. Dapat dilihat dalam tabel 4.

Tabel 4 Maksim Kesederhanaan

\begin{tabular}{|c|c|c|c|}
\hline No. & $\begin{array}{l}\mathrm{Bab} \\
; \mathrm{Hal}\end{array}$ & Tuturan & Analisis \\
\hline 1 & $1 ; 5$ & "Tidak sekolah. Seperti bapaknya." & $\begin{array}{l}\text { Samad memaksimalkan } \\
\text { ketidakhormatan pada dirinya. }\end{array}$ \\
\hline 2 & $1 ; 8$ & $\begin{array}{l}\text { "Kau keliru, Samad. Dialah yang } \\
\text { akan menjagaku. Seperti yang pernah } \\
\text { kau lakukan untuk ayahku dulu." }\end{array}$ & $\begin{array}{l}\text { Tauke mengurangi pujian terhadap } \\
\text { dirinya dengan berkata Bujanglah } \\
\text { yang akan menjaganya. }\end{array}$ \\
\hline 3 & $1 ; 11$ & $\begin{array}{l}\text { "Tapi apa yang kulakukan untuk } \\
\text { bapakmu tidak seberapa, Bujang. } \\
\text { Karena apa yang bapak kau lakukan } \\
\text { untukku jauh lebih besar. Dia }\end{array}$ & $\begin{array}{l}\text { Tauke mengurangi pujian terharap } \\
\text { dirinya dengan mengatakan "Apa } \\
\text { yang kulakukan untuk bapakmu tidak } \\
\text { seberapa.". }\end{array}$ \\
\hline
\end{tabular}




\begin{tabular}{|c|c|c|c|}
\hline & & $\begin{array}{l}\text { menyelamatkan keluargaku berkali- } \\
\text { kali. Dia sangat diandalkan Tauke } \\
\text { Besar, ayahku. Tidak ada pekerjaan } \\
\text { yang tidak tuntas jika diberikan } \\
\text { kepada Samad, anak nuah } \\
\text { kesayangannya. Orang tua itu } \\
\text { meneteskan air mata saat bapak kau } \\
\text { memutuskan berhenti lima belas } \\
\text { tahun lalu." }\end{array}$ & \\
\hline 4 & $2 ; 21$ & $\begin{array}{l}\text { "...Aku sudah berusaha melepaskan } \\
\text { semua catatan gelap milik } \\
\text { keluargaku. Tapi saat aku } \\
\text { melamarmu, memintamu baik-baik, } \\
\text { mereka hanya tertawa. Sakit sekali. } \\
\text { Mereka tidak akan pernah bisa } \\
\text { menerima kenyataan jika aku berbeda } \\
\text { dengan bapakku, si tukang jagal. Aku } \\
\text { terusir dari kampung..." }\end{array}$ & $\begin{array}{l}\text { Samad memaksimalkan } \\
\text { ketidakhormatan pada dirinya dengan } \\
\text { mencaci dirinya yang ditolak ketika } \\
\text { melamar Midah karena ia keturunan } \\
\text { jagal }\end{array}$ \\
\hline 5 & $2 ; 25$ & $\begin{array}{l}\text { "Kau keliru, Samad. Bujanglah yang } \\
\text { akan menjagaku." }\end{array}$ & $\begin{array}{l}\text { Tauke mengurangi pujian terhadap } \\
\text { dirinya, ketika Samad memintanya } \\
\text { menjaga Bujang. }\end{array}$ \\
\hline 6 & $4 ; 47$ & $\begin{array}{l}\text { "Maaf terlambat, Tauke. Aku } \\
\text { berusaha datang sesegera mungkin." }\end{array}$ & $\begin{array}{l}\text { Frans memaksimalkan } \\
\text { ketidakhormatan pada dirinya dengan } \\
\text { meminta maaf atas keterlambatannya. }\end{array}$ \\
\hline 7 & $5 ; 54-56$ & $\begin{array}{l}\text { “...Aku bertahun-tahun ingin menjadi } \\
\text { seperti ayahku dulu., Tauke Besar } \\
\text { sebelumnya. Lantas apa yang aku } \\
\text { dapat setelah menjadi dirinya? Di } \\
\text { kota ini saja keluarga lain tidak } \\
\text { menghormatiku, kita hanya dianggap } \\
\text { keluarga rendah. Jangan tanya di } \\
\text { pulai seberang, Ibu Kota mereka } \\
\text { hanya memincingkan mata tidak } \\
\text { peduli. Kita dianggap sama dengan } \\
\text { preman pasar induk yang kita } \\
\text { taklukkan. Tidak berkelas. Murahan." }\end{array}$ & $\begin{array}{l}\text { Tauke mencaci dirinya yang dulu } \\
\text { juga ingin menjadi seperti Bapaknya, } \\
\text { tetapi dengan menjadi Bapaknya } \\
\text { tidak ada keluarga yang } \\
\text { menghormatinya bahkan keluarga ini } \\
\text { dianggap keluarga rendah. }\end{array}$ \\
\hline 8 & $5 ; 60$ & $\begin{array}{l}\text { "Aku sungguh minta maaf baru } \\
\text { datang setelah Basyir menelpon. Tadi } \\
\text { pagi memang sudah ada pesan yang } \\
\text { disampaikan, aku pikir itu bisa } \\
\text { digantikan oleh orang lain karena } \\
\text { sore ini aku harus pergi ke Hong } \\
\text { Kong. Itu juga tugas dari Tauke yang } \\
\text { tidak kalah prioritasnya. Semua } \\
\text { katamu adalah perintah bagiku." }\end{array}$ & $\begin{array}{l}\text { Bujang meminta maaf karena baru } \\
\text { datang menemui Tauke, padahal } \\
\text { Tauke telah menunggunya dari pagi. }\end{array}$ \\
\hline 9 & $5 ; 65$ & $\begin{array}{l}\text { "Bujang, waktuku hampir habis. Jika } \\
\text { aku tidak mati dalam pertempuran } \\
\text { memperebutkan kekuasaan, ranjang } \\
\text { ini akan membunuhku lebih dulu. } \\
\text { Aku akan segera mengumumkan kau } \\
\text { adalah calon kepala keluarga baru, } \\
\text { setelah kau kembali dari Hong Kong. } \\
\text { Itu akan membuat posisi kita kuat..." }\end{array}$ & $\begin{array}{l}\text { Tauke mencaci dirinya sendiri yang } \\
\text { telah sakit-sakitan, dengan berkata } \\
\text { bahwa waktunya hampir habis. }\end{array}$ \\
\hline 10 & $6 ; 69$ & "Maaf aku terlambat sekali, Edwin." & $\begin{array}{l}\text { Bujang meminta maaf kepada Edwin } \\
\text { atas keterlambatannya dan } \\
\text { mengakibatkan Edwin harus }\end{array}$ \\
\hline
\end{tabular}


menunggu

dst...

e. Maksim Permufakatan

Adapun temuan tuturan yang mematuhi maksim permufakatan dalam novel pulang karya Tere Liye yaitu sebanyak 54 tuturan. Dapat dilihat dalam tabel 5.

Tabel 5 Maksim Permufakatan

\begin{tabular}{|c|c|c|c|}
\hline No. & $\mathrm{Bab} ; \mathrm{Hal}$ & Tuturan & Analisis \\
\hline 1 & $1 ; 6$ & $\begin{array}{l}\text { "Kau mau ikut berburu nanti } \\
\text { petang?" }\end{array}$ & $\begin{array}{l}\text { Tokoh Bujang menanggapi } \\
\text { pertanyaan Tauke dengan anggukan, } \\
\text { yang berarti ia setuju untuk ikut } \\
\text { berburu. }\end{array}$ \\
\hline 2 & $1 ; 6$ & $\begin{array}{l}\text { "Ayolah, Midah. Tauke Muda } \\
\text { memintanya sendiri, dan harus berapa } \\
\text { kali aku bilang, kita tidak bisa } \\
\text { menolak permintaanya. Aku berutang } \\
\text { segalanya." }\end{array}$ & 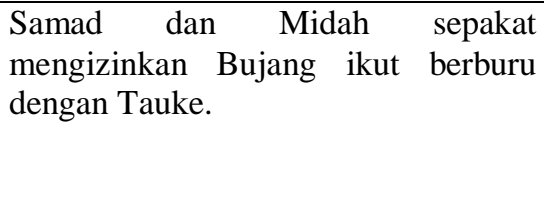 \\
\hline 3 & $1 ; 7$ & $\begin{array}{l}\text { "Mamak mengizinkanmu pergi. Tapi } \\
\text { berjanjilah, kau hanya menonton di } \\
\text { hutan sana, Nak. Kau tidak akan } \\
\text { melakukan apa pun. Hanya menonton } \\
\text { yang lain berburu." }\end{array}$ & $\begin{array}{l}\text { Terjadi kecocokan antara Midah dan } \\
\text { Bujang. Permintaan yang diajukan } \\
\text { Midah disetujui oleh Bujang dengan } \\
\text { menganggukkan kepalanya. }\end{array}$ \\
\hline 4 & $1 ; 7$ & $\begin{array}{l}\text { "Jangan lakukan hal bodoh di rimba } \\
\text { sana! Kau dengar, Bujang?" }\end{array}$ & $\begin{array}{l}\text { Terjadi kecocokan antara Midah dan } \\
\text { Bujang. Permintaan yang diajukan } \\
\text { Midah disetujui oleh Bujang dengan } \\
\text { menganggukkan kepalanya. }\end{array}$ \\
\hline 5 & $1 ; 9$ & $\begin{array}{l}\text { "Selamat, Bujang. Ini babi buruan } \\
\text { pertama kita." }\end{array}$ & $\begin{array}{l}\text { Tauke mengucapkan selamat kepada } \\
\text { Bujang, setelah berhasil } \\
\text { melumpuhkan babi. Serta Bujang } \\
\text { membenarkan perkataan Tauke 'Ini } \\
\text { babi buruan pertama kita.' }\end{array}$ \\
\hline 6 & $1 ; 10$ & $\begin{array}{l}\text { "Kau kenakan jaket hujan ini, } \\
\text { Bujang." }\end{array}$ & $\begin{array}{l}\text { maksim permufakatan ketika Bujang } \\
\text { mengerti lalu mengangguk, yang } \\
\text { artinya ia akan mengenkan jaket } \\
\text { tersebut. }\end{array}$ \\
\hline 7 & $2 ; 23$ & $\begin{array}{l}\text { "Aku tahu kau akan cemas, akan } \\
\text { menjadi apa Bujang besok lusa, } \\
\text { Midah. Kau juga tahu siapa Tauke } \\
\text { Muda itu. Setahu aku sudah lama } \\
\text { melupakan agama. Aku bahkan } \\
\text { membenci ajaran Tuanku Imam sejak } \\
\text { dia sendiri tidak adil menghukum } \\
\text { cinta kita. Tapi jika siang ini, jika } \\
\text { Tuhan memang sayang, maka } \\
\text { anakmu akan menemukan jalan } \\
\text { terbaiknya. Sejauh apa pun dia pergi, } \\
\text { sejauh apapun dia menghilang, Tuhan } \\
\text { akan menemukannya. Biarkan } \\
\text { Bujang ikut Tauke Muda, Midah, aku } \\
\text { mohon. Setidaknya tanyakan pada } \\
\text { Bujang, apakah dia memang ingin } \\
\text { pergi." }\end{array}$ & $\begin{array}{l}\text { mematuhi maksim permufakatan, } \\
\text { ketika Samad menyarankan Midah } \\
\text { untuk bertanya kepada Bujang. } \\
\text { Apakah Bujang memang ingin pergi } \\
\text { bersama Tauke. Lalu Midah } \\
\text { menerima saran tersebut dan bertanya } \\
\text { kepada anaknya, Bujang. }\end{array}$ \\
\hline 8 & $2 ; 23$ & "Apakah kau ingin pergi, Bujang?" & menanyakan \\
\hline
\end{tabular}




\begin{tabular}{|c|c|c|c|}
\hline & & & 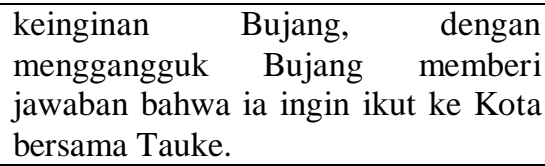 \\
\hline 9 & $2 ; 23$ & $\begin{array}{l}\text { "Berjanjilah kau akan menjaga } \\
\text { perutmu dari semua itu, Bujang. } \\
\text { Agar... Agar besok lusa, jika hitam } \\
\text { seluruh hidupmu, hitam seluruh } \\
\text { hatimu, kau tetap punya satu titik } \\
\text { putih, dan semoga itu berguna. } \\
\text { Memanggilmu pulang." Mamak } \\
\text { mencium ubun-ubunku. } \\
\text { Aku mengangguk. }\end{array}$ & $\begin{array}{l}\text { Bujang menyetujui permintaan } \\
\text { Mamaknya dengan menganggukkan } \\
\text { kepala. }\end{array}$ \\
\hline 10 & $4 ; 38$ & "Baik. Tunggu aku tiga puluh menit." & $\begin{array}{l}\text { Terdapat kecocokan antara Bujang } \\
\text { dan Basyir. Bujang setuju untuk } \\
\text { pulang bertemu Tauke. }\end{array}$ \\
\hline
\end{tabular}

dst...

f. Maksim Kesimpatisan

Adapun temuan tuturan yang mematuhi maksim kesimpatian dalam novel Pulang karya Tere Liye yaitu sebanyak 155 tuturan. Dapat dilihat dalam tabel 6

Tabel 6 Maksim Kesimpatisan

\begin{tabular}{|c|c|c|c|}
\hline No. & $\mathrm{Bab} ; \mathrm{Hal}$ & Tuturan & Analisis \\
\hline 1 & $1 ; 3$ & $\begin{array}{l}\text { "...Astaga! Bagaimana ceritanya kau } \\
\text { bisa tinggal di sini, Samad? Jauh dari } \\
\text { mana pun, seperti di ujung bumi. } \\
\text { Susah sekali kami menemukannya. } \\
\text { Dan menjadi petani?..” }\end{array}$ & $\begin{array}{l}\text { Tokoh Tauke merasa simpati } \\
\text { terhadap Samad, yang rumahnya jauh } \\
\text { dari mana pun serta susah untuk } \\
\text { menemukannya. }\end{array}$ \\
\hline 2 & $1 ; 3$ & $\begin{array}{l}\text { "...Tentu lapar perut setelah } \\
\text { diombang-ambing jalalan berliku." }\end{array}$ & $\begin{array}{l}\text { Samad merasa simpati karena mitra } \\
\text { tuturnya tersebut pasti merasa lapar } \\
\text { setelah diombang-ambil jalanan } \\
\text { berliku untuk sampai ke rumahnya. }\end{array}$ \\
\hline 3 & $1 ; 16$ & "Kau baik-baik saja, Bujang?" & $\begin{array}{l}\text { Tauke merasa simpati dan } \\
\text { menanayakan keadaan Bujang, } \\
\text { setelah melawan babi-babi tersebut. }\end{array}$ \\
\hline 4 & $1 ; 17$ & $\begin{array}{l}\text { "Yang lain pasti menyelamatkan kita. } \\
\text { Jangan cemas, Bujang." }\end{array}$ & $\begin{array}{l}\text { Tauke menjelaskan ke Bujang agar ia } \\
\text { tidak perlu khawatir dan cemas } \\
\text { karena rombongan lain akan } \\
\text { menyelamatkan mereka. }\end{array}$ \\
\hline 5 & $2 ; 21-23$ & $\begin{array}{l}\text { "Biarkan anak kita melihat dunia } \\
\text { luar. Dia tidak akan jadi siapa-siapa } \\
\text { di kampung ini. Tidak sekolah. Tidak } \\
\text { berpengetahuan. Dia sudah lima } \\
\text { belas, entah mau jadi apa dia di sini. } \\
\text { Petani? Penyadap getah damar? Dia } \\
\text { tidak bisa pulang ke kota kecamatan, } \\
\text { bertemu Tuanku Imam karena } \\
\text { keluarga kau pasti mengusirnya, } \\
\text { sama seperti saat mereka } \\
\text { mengusirmu." }\end{array}$ & $\begin{array}{l}\text { Samad merasa simpati kepada } \\
\text { anaknya yang entah akan menjadi apa } \\
\text { ketika menetap di kampung. }\end{array}$ \\
\hline 6 & $2 ; 21-23$ & $\begin{array}{l}\text { "Aku juga tidak ingin berpisah } \\
\text { dengan anak kita, Midah. Tapi kau } \\
\text { seharusnya tahu persis bahwa ini } \\
\text { adalah perjanjian masa lalu. Aku } \\
\text { pernah bilang dengan kau, cepat atau } \\
\text { lambat kau akan melihatnya, }\end{array}$ & $\begin{array}{l}\text { Samad turut merasakan perasaan } \\
\text { istrinya yang tidak ingin berpisah } \\
\text { dengan anak mereka dan berharap } \\
\text { dengan adanya restu istrinya maka, } \\
\text { langkah kaki Bujang akan ringan } \\
\text { untuk ikut bersama Tauke. }\end{array}$ \\
\hline
\end{tabular}




\begin{tabular}{|c|c|c|c|}
\hline & & $\begin{array}{l}\text { menyaksikanya. Cepat atau lambat } \\
\text { kita akan kehilangan anak laki-lak } \\
\text { kita. Biarkan dia pergi dengan } \\
\text { restumu agar langkah kakinya } \\
\text { ringan." }\end{array}$ & \\
\hline 7 & $2 ; 21-23$ & $\begin{array}{l}\text { "Aku tahu kau akan cemas, akan } \\
\text { menjadi apa Bujang besok lusa, } \\
\text { Midah. Kau juga tahu siapa Tauke } \\
\text { Muda itu. Setahu aku sudah lama } \\
\text { melupakan agama. Aku bahkan } \\
\text { membenci ajaran Tuanku Imam sejak } \\
\text { dia sendiri tidak adil menghukum } \\
\text { cinta kita. Tapi jika siang ini, jika } \\
\text { Tuhan memang sayang, maka } \\
\text { anakmu akan menemukan jalan } \\
\text { terbaiknya. Sejauh apa pun dia pergi, } \\
\text { sejauh apapun dia menghilang, Tuhan } \\
\text { akan menemukannya. Biarkan } \\
\text { Bujang ikut Tauke Muda, Midah, aku } \\
\text { mohon. Setidaknya tanyakan pada } \\
\text { Bujang, apakah dia memang ingin } \\
\text { pergi." }\end{array}$ & $\begin{array}{l}\text { Samad turut merasakan perasaan } \\
\text { istrinya cemas akan menjadi apa } \\
\text { Bujang besok lusa dengan ikut } \\
\text { bersama Tauke. }\end{array}$ \\
\hline 8 & $3 ; 35$ & $\begin{array}{l}\text { "Semoga sukses dengan pemilihan } \\
\text { Anda. Selamat siang." }\end{array}$ & $\begin{array}{l}\text { Bujang bersimpati kepada Calon } \\
\text { Presiden dengan mengucapakan } \\
\text { semoga ia sukses dengan pemilihan } \\
\text { yang ia ikuti. }\end{array}$ \\
\hline 9 & $3 ; 35$ & $\begin{array}{l}\text { "Tidak ada sepotongpun kalimatnya } \\
\text { yang bergurau, Pak." }\end{array}$ & $\begin{array}{l}\text { Penasehat ekonomi merasa simpati } \\
\text { kepada Calon Presiden yang terlihat } \\
\text { tegang, meminta penjelasan tentang } \\
\text { apa yang baru saja terjadi. }\end{array}$ \\
\hline 10 & $3 ; 36$ & $\begin{array}{l}\text { "...Itulah kenapa, aku sungguh minta } \\
\text { maaf, terpaksa membatalkan } \\
\text { kampanye di kota lain. Pertemuan ini } \\
\text { sangat penting. Aku tidak bisa } \\
\text { menolak saat mereka memintanya, } \\
\text { atau kita berisiko menghadapi } \\
\text { sesuatu yang berbahaya." }\end{array}$ & $\begin{array}{l}\text { penasehat ekonomi merasa simpati } \\
\text { jika tidak menyetuji pertemuan ini } \\
\text { mereka akan berisiko menghadapi } \\
\text { sesuatu yang berbahaya, sehingga ia } \\
\text { merasa bersalah, meminta maaf } \\
\text { kepada calon presiden karena telah } \\
\text { membatalakan kampanye di kota lain. }\end{array}$ \\
\hline
\end{tabular}

Hasil penelitian di atas merupakan hasil analisis kesantunan berbahasa yang terdapat dalam novel Pulang karya Tere Liye. Dalam menganalisis novel tersebut peneliti menggunakan prinsip kesantunan Leech, yang mengandung enam maksim dan keenam maksim tersebut ditemukan penggunaannya dalam tuturan tokoh dalam novel. Baik maksim kebijaksanaan, maksim kedermawanan, maksim penghargaan, maksim kesederhanaan, maksim permufakatan, ataupun maksim kesimpatian, semuanya dapat ditemukan.

Dalam penelitian ini, terdapat 40 tuturan tokoh yang mematuhi maksim kebijaksanaan, yang dalam penerepannya penutur selalu berusaha mengurangi keuntungannya dan memaksimalkan keuntungan pihak lain. Terdapat 17 tuturan tokoh yang mematuhi maksim kedermawanan, yaitu penutur membuat keuntungan diri sekecil mungkin dan kerugian diri sebesar mungkin. Terdapat 90 tuturan yang mematuhi maksim penghargaan, yaitu penutur diharapkan selalu memberikan penghargaan kepada mitra tutur.

Terdapat 41 tuturan yang mematuhi maksim kesederhanaan, yaitu penutur mengurangi pujian terhadap diri sendiri, memaksimalkan ketidakhormatan pada diri, serta meminimalkan rasa hormat pada diri. Terdapat 54 tuturan yang mematuhi maksim permufakatan, yaitu adanya kecocokan yang 
terjadi antara penutur dan mitra tuturnya. Lalu, terdapat 155 tuturan yang mematuhi maksim kesimpatian, yaitu penutur memaksimalkan sikap simpati kepada pihak lain.

\section{PENUTUP}

Berdasarkan penelitian yang telah dilakukan dengan menganalisis kesantunan berbahasa yang terdapat dalam novel Pulang karya Tere Liye dengan prinsip kesantunan Leech, dapat ditarik kesimpulan bahwa dalam novel Pulang karya Tere Liye terdapat 40 tuturan yang mematuhi maksim kebijaksanaan, 17 tuturan yang mematuhi maksim kedermawanan, 90 tuturan yang mematuhi maksim penghargaan, 41 tuturan yang mematuhi maksim kesederhanaan, 54 tuturan yang mematuhi maksim permufakatan, 155 tuturan yang mematuhi maksim kesimpatian.

\section{DAFTAR PUSTAKA}

Alviah, Iin. 2014. Tindak Tutur Percakapan dalam Novel Sekayu Karya Nh. Dini. (Online)

Aziez, Furqonul \& Abdul Hasim. 2010. Menganalisis Fiksi sebuah Pengantar. Bogor: Ghalia Indonesia.

Chaer, Abdul. 2010. Kesantunan Berbahasa. Jakarta: Rineka Cipta

Chairunnisa. 2016. Analisis Terjemahan kalimat yang Merepresentasikan Tuturan Kesantunan Positif dalam Novel The Host karya Steohenie Meyer. (Online)

Dirgantara, Yuana Agus. 2012. Pelangi Bahasa Sastra dan Budaya Indonesia. : Garudhawaca.
Kridalaksana, Harimurti. 2008. Kamus Linguistik. Jakarta: PT. Gramedia.

Leech, Geoffrey. 1993. Prinsip-prinsip Pragmatik. Jakarta: Penerbit Universitas Indonesia (UI-Press)

Nadar, F.X. 2009. Pragmatik \& Penelitian Kualitatif. Jogjakarta: Graha Ilmu.

Nurdaniah, Mia. 2014. Prinsip Kesantunan Berbahasa Menurut Leech pada Novel Pertemuan Dua Hati Karya Nh. Dini dan Implikasinya terhadap Pembelajaran Bahasa Indonesia di SMA. (Online)

Nurgiyantoro, Burhan 2009. Penilaian Pengajaran Bahasa. Yogyakarta:BPFE

Nurgiantoro, Burhan. 2010. Teori Pengkajian Fiksi. Yogyakarta: Gadjah Mada University Press.

Pranowo. 2009. Berbahasa Secara Santun. Yogyakarta: Pustaka Pelajar.

Rahardi,R. Kunjana. 2005. Pragmatik Kesantunan Imperatif Bahasa Indonesia. Jakarta: Erlangga.

Sadapotto, Andi dan Muhammad Hanafi. 2016. "Kesantunan Berbahasa dalam Perspektif Pragmatik". Proceedings The Progressive and Fun Education Seminar. Sumatera Utara, Agustus 2016.

Susanto, Dwi. 2012. Pengantar Teori Sastra. Yogyakarta: Cups.

Wijana, I Dewa.1996. Dasat-dasar Pragmatik. Yogyakarta: ANDI. 